\title{
Evaluation of Traffic Carried by ATM Wireless Access Link Controlled by MEDIAN Protocol
}

\author{
Andrzej Beben, Wojciech Burakowski and Piotr Pyda \\ Institute of Telecommunications, Warsaw University of Technology \\ Military Communication Institute, Zegrze \\ E-mail:abeben@tele.pw.edu.pl
}

Key words: wireless ATM, PRMA, CAC, QoS requirements, MEDIAN access protocol

Abstract: The paper points out on some limitations introduced by access points in wireless ATM network that have great impact on supporting end-to-end communication services with QoS requirements like CBR, VBR, $\mathrm{ABR}$ and GFR. Analysed access protocol is MEDIAN [5], which belongs to PRMA (Packet Reservation Medium Access) class and works under TDMA scheme. It appears that internal MEDIAN mechanisms (like frame structure, cell reservation mechanism and error protection) could radically reduce available link capacity designated for handling traffic with guaranteed QoS requirements. The formulas for evaluation this capacity are provided in the paper. Limitations for the CAC function are also discussed. Exemplary numerical results illustrating quality of transferred traffic are included.

\section{INTRODUCTION}

In 1996, the ATM Forum Wireless Working Group started work on the standards for the wireless ATM network (WATM) [12]. In order to adopt the ATM technology to a wireless environment, many problems should be solved because of high bit error rates in radio links and specific medium access protocols [1], [2]. However, solving these problems requires introduction of additional overheads necessary for access control, error protection and link organisation (frame structure, reservation mechanism) [3]. Anyway, the objective of wireless ATM network is to provide the same 
communication services as these supported by cable network (with similar QoS requirements) and this requires implementation of appropriate traffic control mechanisms also in the wireless access points [4].

The paper points out on some limitations introduced by access points in wireless ATM network having great impact on supporting end_to_end communication services with $\mathrm{QOS}$ requirements like $\mathrm{CBR}, \mathrm{VBR}, \overline{\mathrm{ABR}}$ and GFR. Analysed access protocols, called PRMA (Packet Reservation Medium Access), belong to the family of TDMA class. More precisely, the MEDIAN protocol [5], as representative of this class is taken into account for our considerations. Effective traffic control (preventive and reactive) demands the precise knowledge of such parameters as available bandwidth and cell delay characteristics introduced by each hop (switch, access point) along the connection [9]. On the contrary to the cable link, the capacity available for the traffic on the wireless access point in much less than the link bit-rate while the cell delay and its variation is significantly larger. This is mainly due to additional overhead for access control, error protection and some limitations corresponding to the link organisation. Notice that available link capacity and cell delay characteristics in RAP (Radio Access Point) should be known a priori for performing CAC function. Evaluation of current available capacity is also strongly required for ABR service.

The paper provides an estimation of the available capacity in the RAP governed by the MEDIAN protocol. These considerations take into account the limitations corresponding to the internal access control protocol behaviour (frame structure, reservation mechanism, and error protection). Next, we point out on the conditions for the CAC performing. More specifically, estimation of the CDV (Cell Delay Variation) characteristics introduced by RAP is investigated. Recall that for some types on ATM connections, not only the CLR (Cell Loss Ratio) but also CDV value is also important. An excellent example of such connection is CBR connection, requiring rather small values of the CDV [8], [10]. On the other hand, correct estimation of the CDV values is necessary to avoid cell losses caused by the access protocol. Exemplary rules for tuning parameters assuming MEDIAN protocol are outlined. Finally, some exemplary numerical results are presented to illustrate consequences of admission traffics (of CBR and VBR types) up to full available capacity.

Organisation of the paper is as follows. Section 2 shortly describes the features of the MEDIAN protocol. The factors that result for reducing available bandwidth and related to the internal protocol mechanisms having great impact on traffic control are explained in section 3. Some numerical results showing the bandwidth limitations for the CAC function are shown in section 4 . Finally, the conclusions are outlined in section 5 . 


\section{BRIEF MEDIAN DESCRIPTION}

In wireless ATM network a part of user terminals is attached to the fixed network by wireless links terminated in RAP unit, as depicted in Figure 1. For these terminals the access to the network is governed by special MAC protocol.
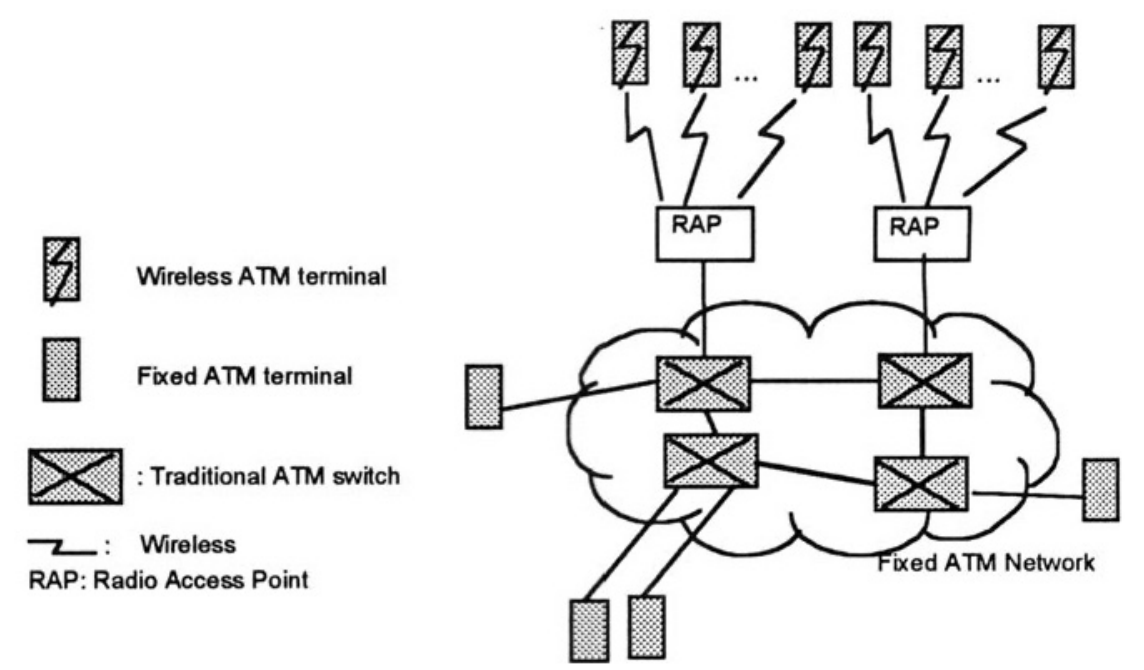

Figure 1. Wireless ATM network scenario

For the purpose of the wireless ATM network a number of new MAC protocols was recently submitted, which belong to the TDMA (Time Division Multiple Access) or CDMA (Code Division Multiple Access) class. In this paper we focus on the MEDIAN [5] protocol working under TDMA scheme. In fact, one can find also other protocols belonging to the considered class, like MASCARA [7] or SAMBA [6]. Detailed performance studies of these protocols are out of the scope of this paper. Anyway, all of mentioned protocols assume that the time slot allocation for a given connection is made dynamically. Therefore, some conclusions corresponding to the MEDIAN protocol behaviour can be the same for all protocols of the studied class.

In order to complete the paper, a short introduction to the MEDIAN protocol is provided below. Figure 2 depicts the frame format assumed for communication between mobile terminals and the base station. This frame consists of 64 slots, among them 61 are designated for the cell transferring while the rest are for sending control information (for synchronisation, broadcast and contention slots). Notice that this frame is for both up and 
down transmission. The number of slots designated for one of these directions depends on the current load conditions.

The base station dynamically allocates these 61 slots only for running connections. The updating process is made frame by frame on the basis of received reservation requests from end terminals for up transmission and from the base station for down transmission. In the case when the number of required reservations is smaller that 61 , the rest slots in the frame are allocated according to a predefined pattern, which is assumed as equally distributed among connection being in progress. These slots are called polling slots. Notice that when the system is working under low load conditions then no reservations are generated since polling mechanism is sufficient to serve submitted traffic. On the contrary, high traffic load usually demands some reservations.

The active terminal sends its reservation requests only in these slots that is dedicated to it, using the piggybacking scheme. The mechanism governing the allocation of slots takes into account the number of received requests, their arriving times and priority of the connection. More precisely, in MEDIAN protocol pure priority scheme is not implemented. For each connection there is assigned a kind of priority that is expressed by the maximum allowed time (denoted as $\Delta_{\max }$ ) the cell can wait for sending to the base station. When this time terminates then the waiting cell is simply lost. Notice however that such mechanism does not guarantee that the cell from the higher priority connection could be served after a cell of lower priority. As a consequence, the applied EDD (Early Due to Date) scheduling with the above described cell discarding scheme does not support the possibility to reserve a fixed number of slots in consecutive transmission frames, what is extremely required e.g. for CBR connections. Therefore, cell transfer delay of consecutive cells depends on the traffic load conditions.

Similarly, the base station sends the requests for down transmission. In this case, the request for the slot reservation is generated when a cell from the network joins the base station. The requests arriving from the base stations and end terminals are served according to the expiration time values of particular cells. The cell with lower this value is served before. Anyway, inside one frame the cells for down transmission are served as the first.

More detailed description of the MEDIAN one can find in [5]. 


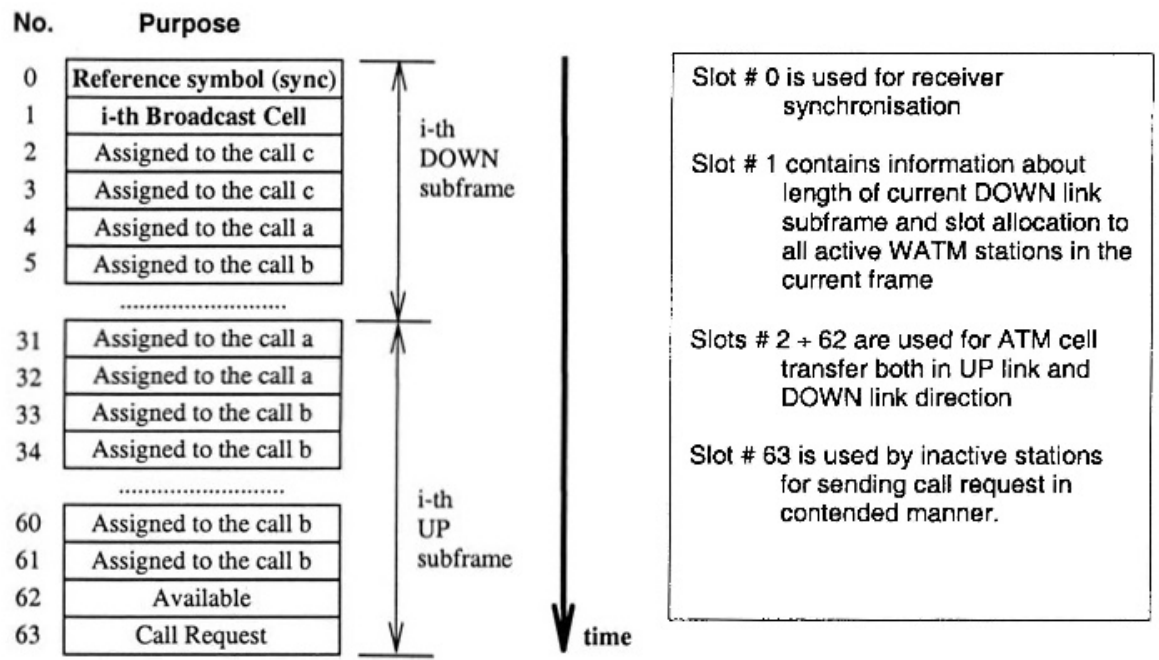

Figure 2 - Exemplary MEDIAN frame format in the case of three running connections, say a, $b$ and $c$

\section{GUARANTEED TRAFFIC SUPPORTED BY MEDIAN}

In this section we investigate the limitations introduced by RAP controlled by MEDIAN protocol which have great impact on supporting end_to_end ATM communication services demanding bandwidth allocation, like CBR, VBR, ABR and GFR. Recall that effective traffic control (preventive and reactive) demands the precise knowledge of such parameters as available bandwidth and cell delay characteristics introduced by each hop (switch, access point) along the connection. On the contrary to the cable link, one can expect that capacity available for the guaranteed traffic on the wireless access point is much less than the link bit-rate while the cell delay and its variation is significantly larger. This is mainly due to additional overhead for access control, error protection and some limitations corresponding to the link organisation.

\subsection{Estimation of available link capacity}

As it was stated above, one can expect that capacity available for traffic in the access link is reduced comparing to the link bit-rate. In this section we will explain the factors causing this. 
The formula for available capacity, $\mathrm{C}_{\mathrm{av}}$, of the access link with $\mathrm{C}$ kbps is the following:

$$
C_{a v}=C * \frac{N-M}{N} * a * r * b,
$$

where:

$a:$ is the ratio of the cell to slot time duration; this is called guard time. The value $a$ is usually smaller than 1 . Minimum value of parameter a depends on the assumed maximum distance between mobile terminal and the base station. For instance, $a=0.7$ for the link of 2048 kbps (E1 link) with GSM cell of $35 \mathrm{~km}$. Exact value of a is tuned after measurements made in real system. Notice that for the indoor system $a$ is closed to 1 while for outdoor systems a is much less than 1 ;

$\mathrm{r}$ : is the code rate resulting from application of redundancy code; for instance, using the Reed-Salomon code $(71,55), r=55 / 71$;

$\mathrm{b}$ : is the coefficient related to the assumed cell format in the access comparing to the standard; $b=53 /(53+2)$ for MEDIAN;

$\mathrm{N}$ : is number of slots in the frame; $\mathrm{N}=64$ for the MEDIAN;

$M$ : is number of control slots in the frame; $M=3$ for MEDIAN (for synchronisation, broadcast and contention slots);

For instance, $\mathrm{C}_{\mathrm{av}}=728.5 \mathrm{kbps}$ for the link with $\mathrm{C}=2048 \mathrm{kbps}, \mathrm{a}=0.5$, $r=55 / 71$ and $b=53 / 55$. Notice that in this example the available capacity is reduced about 3 times (!) comparing to the link bit-rate. Anyway, only this capacity can be considered for serving traffic demanding guaranteed bandwidth in the wireless access link.

However, the estimated available link capacity is for two directions, up and down.

\subsection{Conditions for the CAC}

The discussed in this section issue corresponds to additional conditions for the MAC protocol for performing CAC function assuming that the wireless link capacity is evaluated by (1). Recall that CAC consists in refusing a new call if the addition of its traffic would lead to an unacceptable quality of service level for that or any previously accepted traffic.

Unfortunately, the implementation details of MAC protocol could introduce additional reducing of available bandwidth causing by: (1) incorrect setting of protocol parameters, (2) unpredictable protocol 
behaviour under high load conditions. Below, we show that the above limitations could lead to significant traffic service quality degradation. As example, we will examine the MEDIAN protocol, but the conclusions are more general.

\subsubsection{Setting protocol parameters}

In the MEDIAN protocol, it appears that $\Delta_{\max }$ values assigned for each connection have essential impact on quality of carried traffic. Small $\Delta_{\max }$ could cause cell loses because of allowed waiting time expiration while too large $\Delta_{\max }$ usually leads to large $\mathrm{CDV}$, non acceptable e.g. for CBR connections.

Let assume that $\mathrm{N}_{U P}$ running connections pass a RAP unit and, for the simplicity, all of them are of simplex type with up direction. The i-th connection, $i=1, \ldots, N_{U P}$, is characterised by its negotiated PCR(i) value. The following condition should be satisfied in order to avoid cell losses inside the connection i, caused by assumed TDMA frame structure:

$$
\Delta_{\max }(i) \geq\left(4+\left(\sum_{k=1}^{N_{U P}}\left[\frac{P C R(k)}{P C R(i)}\right]-1\right)\right) * t_{s}
$$

where $t_{s}$ denotes time slot duration, $t_{s}=53 * 8 /(C * a * r * b)$.

Explanation of the formula (2) is the following. Under the worst case scenario, a cell from the i-th connection can wait for its transmission by the time required for three control slots (contention, synchronisation and broadcast, see Fig. 1) and for transferring cells belonging to the rest $(\mathrm{N}-1)$ running connections. Therefore, the number of such cells from the k-th connection with $\operatorname{PCR}(\mathrm{k})$ is $(\operatorname{PCR}(\mathrm{k}) / \mathrm{PCR}(\mathrm{i}))^{+}$.

Notice that (2) evaluates minimum CDV value the protocol guarantees.

\subsubsection{Low load conditions}

In this section we will argue that MEDIAN protocol can guarantee reasonable CDV values only in the case when it works under polling regime only (see section 2). For such conditions, the slots in the frame are assigned for given connection in a predefined pattern and are fixed during the connections are running. The cells waiting for up and down transmission are served in the dedicated slots only. 
Consider the traffic carried by the system is generated along $N_{U P}$ and $\mathrm{N}_{\text {Down }}$ connections, each of them is of CBR or VBR type. Each connection is characterised by its own PCR value.

The provided below analysis is derived from the point of view of the up connections. The condition that such system will work on the basis of polling scheme only is satisfied when maximum one cell from each connection can wait for its up transmission.

The number of slots $\mathrm{L}_{\mathrm{DOWN}}$, dedicated to the down connections, and transferred at the beginning of each MEDIAN frame is done by the formula:

$$
L_{\text {DOWN }}=\sum_{i=1}^{N_{\text {DOWN }}}\left\lceil\frac{64^{*} t_{S}^{*} P C R_{i}}{53^{*} 8}\right\rceil=\sum_{i=1}^{N_{\text {DOWN }}}\left\lceil\frac{64^{*} P C R_{i}}{C^{*} a^{*} r^{*} b}\right\rceil,
$$

where $\mathrm{PCR}_{\mathrm{i}}$ is the peak cell rate value of the $\mathrm{i}$-th connection, $\mathrm{i}=1, \ldots$, Nown.

As a consequence, the low load conditions (serving according to the polling scheme only) are satisfy when:

$$
\frac{53 * 8}{\max _{i=1, \ldots, N_{U P}}\left\{P C R_{i}\right\}}>t_{s}^{*}\left(4+\left(N_{U P}-1\right)+L_{D O W N}\right),
$$

Finally, the formula (5) gives the maximum number of connections, the system can support keeping low load conditions.

$$
N_{U P}<\frac{C^{*} a * r * b}{\max _{i=1, \ldots, N_{U P}}\left\{P C R_{i}\right\}}-3-L_{D O W N}
$$

For this case, the minimum CDV value (minimum $\Delta_{\max }$ ) the system can guarantee without cell loses is:

$$
\Delta_{\max }> \begin{cases}t_{s}^{*}\left(4+\left(N_{U P}-1\right)+L_{D O W N}\right), & \text { UP direction } \\ t_{s} *\left(64+L_{D O W N}-1\right), & \text { DOWN direction }\end{cases}
$$

Remark that number of connections the MEDIAN can support is conditioned by the maximum PCR value. 


\subsubsection{Unpredictable protocol behaviour under high load conditions}

High load conditions in the wireless link could lead to cell transfer quality degradation. This is mainly caused by non-ideal slot reservation mechanism, which allows that some slots are transferred as empty despite that cells are waiting for transmission.

This is caused by the fact that more slot reservations than required are made by the protocol since a number of waiting cells is served by polling. As a consequence, such non-work conserving system behaviour leads to significantly larger CDV. Setting $\Delta_{\max }$ for each connection according to (6) results that CLR essentially grows in the case of high load conditions.

\section{NUMERICAL EXAMPLES}

In this section we will show exemplary numerical results illustrating what one can expect about cell transfer characteristics when the RAP is controlled by MEDIAN protocol. These characteristics will be provided in terms of CDV and CLR parameters. More precisely, we will show the minimum $C D V$ values satisfying that $C L R=0$. In the numerical examples we assumed that the link capacity $\mathrm{C}=2.048 \mathrm{kbps}$ while $\mathrm{C}_{\mathrm{av}}=728.5 \mathrm{kbps}(\mathrm{a}=0.5, \mathrm{r}=55 / 71$ and $b=53 / 55$ ).

The following types of connections were taken into account:

1. CBR connections:

- CBR\#1: with PCR=72,2 kbps (equivalent to $64 \mathrm{kbps}, 8 \mathrm{kbps}$ is for AAL1 and ATM headers [11]),

- CBR\#2: with PCR=18 kbps (equivalent to $16 \mathrm{kbps}, 2 \mathrm{kbps}$ is for AAL1 and ATM headers).

2. VBR connections:

- VBR\#1: ON/OFF source with $\mathrm{PCR}=72,2 \mathrm{kbps}$ (with conditions as for CBR\#1), mean burst duration: $350 \mathrm{msec}$, mean silence duration: 650 msec (VBR voice traffic model for PCM modulation technique),

- VBR\#2: ON/OFF source with $P C R=18 \mathrm{kbps}$ (with conditions as for CBR\#2), mean burst duration: $350 \mathrm{msec}$, mean silence duration: 650 msec (VBR voice traffic model for LD-CELP modulation technique).

The presented below results correspond to two cases: (1) the cells are transmitted only to the up direction (from the terminals to the base station), (2) the cells transferred by the wireless link are transmitted to both up and down directions. 


\section{Case study no. 1: cells are transferred to the up direction only}

The experiments were provided assuming that a number of identical types of connections are in progress, which are CBR\#1, CBR\#2, VBR\#1 or VBR\#2. The obtained simulation and theoretical (see formula (6)) results are reported in the tables 1-4. For each case, one can observe "low" and "high" traffic load conditions (see formula (4) and (5)). As it was expected, when the traffic is low then the CDV values are similar to these calculated by formula (6). On the other hand, high load conditions occurring on the considered link cause very large CDV that could be slightly accepted e.g. for CBR connections. Therefore, we stress that correct admission control with predictable CDV values is only possible under low load conditions. This is of course undesirable since the available bandwidth in the wireless access link is reduced again. For instance, the upper bound for low load conditions is:

- for CBR\#1 connections: 7* 72,2 kbps $=505 \mathrm{kbps}$;

- for CBR\#2 connections: $38 * 18 \mathrm{kbps}=684 \mathrm{kbps}$;

- for VBR\#1 connections: $7 * 72,2 \mathrm{kbps} * 0.35=177 \mathrm{kbps}$;

- for CBR\#1 connections: $38 * 18 \mathrm{kbps} * 0.35=240 \mathrm{kbps}$;

(in the analysed cases $\mathrm{C}_{\mathrm{av}}=728.5 \mathrm{kbps}$ ).

On the basis of these results one can conclude as follows:

- Admission control with predictable CDV values is only possible on the basis of PCR declarations; therefore number of admitted connections does not depend on type of connection, CBR or VBR;

- Upper bound for keeping low load conditions can be determined on the basis of the PCR declarations;

- Effective bandwidth utilisation is lower in the case of VBR connections.

Table 1: CDV values for identical CBR connections with PCR=72,2 kbps, CLR=0

\begin{tabular}{|l|c|c|c|c|c|c|c|}
\hline \multirow{2}{*}{} & \multicolumn{6}{|c|}{ Number of running CBR connections (UP direction) } \\
\cline { 2 - 8 } & 1 & 3 & 5 & 7 & 8 & 9 & 10 \\
\cline { 2 - 7 } & \multicolumn{6}{|c|}{ Low load } & \multicolumn{3}{c|}{ High load } \\
\hline $\begin{array}{l}\text { CDV [ms] } \\
\text { Simulation } \\
\text { results }\end{array}$ & 2.21 & 3.32 & 4.43 & 5.54 & 9.72 & 29.8 & 184.26 \\
\hline $\begin{array}{l}\text { CDV [ms] } \\
\text { Theoretical } \\
\text { results }\end{array}$ & 2.22 & 3.33 & 4.44 & 5.55 & - & - & - \\
\hline
\end{tabular}


Table 2: $\mathrm{CDV}$ values for identical CBR connections with $\mathrm{PCR}=18 \mathrm{kbps}, \mathrm{CLR}=0$

\begin{tabular}{|c|c|c|c|c|c|c|c|c|c|c|c|}
\hline & \multicolumn{11}{|c|}{ Number of running CBR connections (UP direction) } \\
\hline & 1 & 3 & 5 & 7 & 10 & 15 & 25 & 30 & 35 & 38 & 39 \\
\hline & \multicolumn{10}{|c|}{ Low load } & $\begin{array}{l}\text { High } \\
\text { load }\end{array}$ \\
\hline $\begin{array}{l}\text { CDV [ms] } \\
\text { Simulation } \\
\text { results }\end{array}$ & 2.11 & 3.31 & 4.43 & 5.54 & 7.20 & 9.97 & $\begin{array}{c}15.5 \\
3\end{array}$ & $\begin{array}{c}18.3 \\
0\end{array}$ & $\begin{array}{c}21.0 \\
7\end{array}$ & $\begin{array}{c}22.7 \\
4\end{array}$ & 128.0 \\
\hline $\begin{array}{l}\text { CDV [ms] } \\
\text { Theoretical } \\
\text { results }\end{array}$ & 2.22 & 3.33 & 4.44 & 5.55 & 7.21 & 9.99 & $\begin{array}{c}15.5 \\
4\end{array}$ & $\begin{array}{c}18.3 \\
1\end{array}$ & $\begin{array}{c}21.0 \\
8\end{array}$ & $\begin{array}{c}22.7 \\
5\end{array}$ & - \\
\hline
\end{tabular}

Table 3: CDV values for identical VBR connections with PCR=72,2 kbps, CLR=0

\begin{tabular}{|l|c|c|c|c|c|c|c|c|c|c|}
\hline \multirow{2}{*}{} & \multicolumn{8}{|c|}{ Number of running VBR connections (UP direction) } \\
\cline { 2 - 9 } & 1 & 3 & 5 & 7 & 8 & 10 & 15 & 20 & 25 & 30 \\
\cline { 2 - 8 } & \multicolumn{6}{|c|}{ Low load } & \multicolumn{6}{c|}{ High load } \\
\hline $\begin{array}{l}\text { CDV [ms] } \\
\begin{array}{l}\text { Simulation } \\
\text { results }\end{array}\end{array}$ & 2.20 & 3.32 & 4.43 & 5.54 & 7.21 & 29.0 & 215.0 & 927.0 & 3045.0 & 20000.0 \\
\hdashline $\begin{array}{l}\text { CDV [ms] } \\
\text { Theoretical } \\
\text { results }\end{array}$ & 2.22 & 3.33 & 4.44 & 5.55 & - & - & - & - & - & - \\
\hline
\end{tabular}

Table 4: CDV values for identical VBR connections with $P C R=18 \mathrm{kbps}, \mathrm{CLR}=0$

\begin{tabular}{|l|c|c|c|c|c|c|c|c|c|}
\hline \multirow{2}{*}{} & \multicolumn{8}{|c|}{ Number of running VBR connections (UP direction) } \\
\cline { 2 - 9 } & 1 & 3 & 5 & 10 & 20 & 30 & 38 & 40 & 50 \\
\cline { 2 - 8 } & \multicolumn{8}{|c|}{ Low load } \\
\hline $\begin{array}{l}\text { CDV [ms] } \\
\text { Simulation } \\
\text { results }\end{array}$ & 2.2 & 3.32 & 4.43 & 7.20 & 12.75 & 18.30 & 22.7 & 26.5 & 58.1 \\
\hdashline $\begin{array}{l}\text { CDV [ms] } \\
\text { Theoretical } \\
\text { results }\end{array}$ & 2.22 & 3.33 & 4.44 & 7.21 & 12.75 & 18.31 & 22.7 & - & - \\
\hline
\end{tabular}

\section{Case study no. 2: cells are transferred to the up and to the down}

Tables 5-6 show the exemplary results corresponding to the case of identical CBR (CBR\#1 or CBR\#2) connections with up and down directions. The reported CDV values are related to the up connections only. It appears that for the considered set of CBR\#1 connections, the system behaves on the high load conditions (the formula (5) is not valid) only. Despite that one can observe small CDV values they are not predictable, what is very important for the CAC function. In the case of CBR\#2 connections (see Table\#6), low and high load conditions are clear. However, the conclusions are similar to these form the case study no. 1 . 
Table 5: $\mathrm{CDV}$ values for $\mathrm{CBR}$ bi-directional up connections with $\mathrm{PCR}=72.2, \mathrm{CLR}=0$

\begin{tabular}{|c|c|c|c|c|c|c|c|c|c|}
\hline \multicolumn{1}{|c|}{ Number of running CBR connections (UP \& DOWN direction) } \\
\hline \begin{tabular}{l} 
DOWN kbps \\
\hline $\begin{array}{l}\text { UP } \\
72 \text { kbps }\end{array}$
\end{tabular} & 1 & 1 & 1 & 1 & 1 & 1 & 1 & 1 & 1 \\
\hline \begin{tabular}{l} 
CDV [ms] \\
Simulation \\
results \\
\hdashline $\begin{array}{l}\text { CDV [ms] } \\
\text { Theoretical } \\
\text { results }\end{array}$
\end{tabular} & 5.57 & 6.65 & 7.76 & 8.98 & 10.25 & 14.38 & 20.83 & 30.73 & 2000 \\
\hline
\end{tabular}

Table 6: $\mathrm{CDV}$ values for $\mathrm{CBR}$ bi-directional up connections with $\mathrm{PCR}=18 \mathrm{kbps}, \mathrm{CLR}=0$

\begin{tabular}{|c|c|c|c|c|c|c|c|c|c|}
\hline \multicolumn{1}{|c|}{ Number of running CBR connections (UP \& DOWN direction) } \\
\hline $\begin{array}{c}\text { DOWN } \\
18 \text { kbs }\end{array}$ & 1 & 1 & 1 & 1 & 1 & 1 & 1 & 1 & 1 \\
\hline $\begin{array}{c}\text { UP } \\
18 \mathrm{kbps}\end{array}$ & 1 & 5 & 10 & 15 & 20 & 25 & 30 & 36 & 39 \\
\hline & \multicolumn{7}{|c|}{ Low load } & $\begin{array}{c}\text { High } \\
\text { load }\end{array}$ \\
\hline $\begin{array}{l}\text { CDV [ms] } \\
\text { Simulation } \\
\text { results }\end{array}$ & 3.32 & 5.54 & 8.31 & 11.09 & $\begin{array}{c}13.8 \\
6\end{array}$ & 16.64 & 19.41 & 22.74 & 1500 \\
$\begin{array}{l}\text { CDV [ms] } \\
\text { Theoretical } \\
\text { results }\end{array}$ & 3.33 & 5.55 & 8.32 & 11.09 & 13.8 & 16.65 & 19.42 & 22.75 & - \\
\hline
\end{tabular}

Finally, tables 7 and 8 show the CDV values of CBR up connections for the case with a mix of CBR\#1 and CBR\#2. These results confirm the above conclusions. Similar experiments were provided for the VBR\#1 and VBR\#2 traffics. 
Table 7: $\mathrm{CDV}$ values for $\mathrm{CBR}$ up connections with $\mathrm{PCR}=18 \mathrm{kbps}$ and $\mathrm{PCR}=72.2, \mathrm{CLR}=0$

\begin{tabular}{|l|c|c|c|c|c|c|c|c|c|}
\hline \multicolumn{8}{|c|}{ Number of running CBR connections (UP \& DOWN direction) } \\
\hline $\begin{array}{c}\text { DOWN } \\
\text { CBR\#2 } \\
(18 \text { kbps) }\end{array}$ & 1 & 1 & 1 & 1 & 1 & 1 & 1 & 1 & 1 \\
\hline $\begin{array}{c}\text { UP } \\
\text { CBR\#1 } \\
\text { (72 kbps) }\end{array}$ & 1 & 2 & 3 & 4 & 5 & 6 & 7 & 8 & 9 \\
\hline & \multicolumn{7}{|c|}{ Low load } \\
\hline $\begin{array}{l}\text { CDV [ms] } \\
\text { Simulation } \\
\text { results }\end{array}$ & 3.32 & 3.88 & 4.43 & 4.99 & 5.54 & 7.17 & 9.28 & 23.38 & 34.95 \\
\hline $\begin{array}{l}\text { CDV [ms] } \\
\text { Theoretical } \\
\text { results }\end{array}$ & 3.33 & 3.88 & 4.44 & 4.99 & 5.55 & - & - & - & - \\
\hline
\end{tabular}

Table 8: $\mathrm{CDV}$ values for $\mathrm{CBR}$ up connections with $\mathrm{PCR}=18 \mathrm{kbps}$ and $\mathrm{PCR}=72.2, \mathrm{CLR}=0$

\begin{tabular}{|l|c|c|c|c|c|c|c|c|c|}
\hline \multicolumn{1}{|c|}{ Number of running CBR connections (UP \& DOWN direction) } \\
\hline $\begin{array}{c}\text { DOWN } \\
\text { (CBR\#2) } \\
\text { 18 kbps }\end{array}$ & 2 & 2 & 2 & 2 & 2 & 2 & 2 & 2 & 2 \\
\hline $\begin{array}{c}\text { UP } \\
\text { CBR\#1 } \\
(72 \text { kbps) }\end{array}$ & 1 & 2 & 3 & 4 & 5 & 6 & 7 & 8 & 9 \\
\hline & \multicolumn{7}{|c|}{ Low load } & \multicolumn{7}{|c|}{ High load } \\
\hline $\begin{array}{l}\text { CDV [ms] } \\
\text { Simulation } \\
\text { results } \\
\begin{array}{l}\text { CDV [ms] } \\
\text { Theoretical } \\
\text { results }\end{array}\end{array}$ & 4.43 & 4.98 & 5.54 & 6.1 & 7.63 & 8.87 & 17.95 & 25.74 & 42.14 \\
\hline
\end{tabular}

\section{SUMMARY}

The paper evaluated ATM wireless access link controlled by MEDIAN protocol from the point of view of its ability for providing effective admission control. It appears that organisation of such link causes several limitations resulting that its available bit-rate capacity is significantly smaller than one can expect. The factors that have main impact on this are: (1) necessary overhead for providing appropriate frame structure, error protection mechanism and handling long distance terminals, (2) double slot reservation and polling mechanisms for assigning frame slots to active terminals. As a consequence, for the connections requiring rigorous QoS with respect to allowed maximum CDV, like e.g. these dedicated for voice 
transferring, the allowed traffic load in the RAP should be rather low. The presented exemplary numerical results show that for the case of high link utilisation CDV values are large and unpredictable. The upper bound of the link capacity available for performing CAC function can be evaluated by formulas presented in the paper.

\section{REFERENCES}

[1] B.Sklar „Rayleigh Fading Channels in Mobile Digital Communication Systems Part I: Characterization", IEEE Communication Magazine, September 1997

[2] B.Sklar „Rayleigh Fading Channels in Mobile Digital Communication Systems Part II: Mitigation", IEEE Communication Magazine, September 1997

[3] J.B. Cain, D. N. McGregor, ,A recommended error control architecture for ATM networks with wireless links", IEEE Journal on Selected Areas in Communications Vol. 15 No. 1 January 1997

[4] A. Bak, A.Beben, W.Burakowski, Z.Kopertowski, P.Pyda, M. Lesniewicz „Quality of ATM Layer Services in Wireless Networks", Polish Teletraffic Symposium, Szklarska Poreba, Poland, 1999.

[5] ACTS Program Median develops a $60 \mathrm{GHz}$ wireless LAN, (http://www.tno.nl/instit/fel/div3/median.html")

[6] ACTS 2004 Program SAMBA - System for Advanced Mobile Broadband Application (http://hostira.cet.pt/samba/Index.html)

[7] Frederic Bauchot, Stephane Decrauzat, Gerard Marmigcre, Lazaros Merakos, Nikos Passas , „MASCARA, a MAC protocol for wireless” (http://www.tik.ee.ethz.ch/ wand/DOCUMENTS/documents-frame.html)

[8] Markku Niemi, ,Application Requirements for WATM”, ATM Forum document no. 961058.

[9] J.Roberts, U. Mocci, J. Virtamo (Eds.), „Broadband Network Teletraffic. Performance Evaluation and Design of Broadband Multiservice Networks. Final Report of Action COST 242", 1996

[10] M. Noorchashm, B. Bharucha, and G. Wetzel, ,Buffer Design for Constant Bit Rate Services in Presence of Cell Delay Variation", ATM Forum document no. 95-1454.

[11] Recommendation ITU-T I.363, „B-ISDN ATM Adaptation Layer (AAL) Specification”

[12] R.R. Bhat, „Draft baseline text for Wireless ATM Capability Set 1 Specification”, ATM Forum document BTD-WATM-01.10, December 1998 